\title{
Cost-Effectiveness of ${ }^{99 m}$ Tc-Sestamibi in Predicting Response to Chemotherapy in Patients with Lung Cancer: Systematic Review and Meta-Analysis
}

\author{
Hosahalli K. Mohan ${ }^{1}$ and Kenneth A. Miles ${ }^{2}$ \\ ${ }^{1}$ Department of Nuclear Medicine, Guys \& St. Thomas Hospitals, NHS Trust, London, United Kingdom; and ${ }^{2}$ Brighton and Sussex \\ Medical School, University of Sussex, Brighton, United Kingdom
}

Multidrug resistance (MDR) is a major problem in lung cancer. 99mTc-methoxyisobutylisonitrile (99mTc-MIBI) has been demonstrated to be a noninvasive marker for the diagnosis of MDRrelated $\mathrm{P}$ glycoprotein and MDR-associated protein expression in various solid tumors. Studies have shown that $99 \mathrm{mTC}-\mathrm{MIBI}$ could play a significant role in the management of lung cancer; for example, it could be used in the selection of patients for chemotherapy or radiotherapy or in combined protocols before the start of treatment. Accurate selection of chemosensitive patients with ${ }^{99 m}$ Tc-MIBI would result not only in effective treatment of patients but also in significant cost savings for health care providers. There is increasing pressure on health care providers to consider costs in medical decision making, particularly in the last decade, as several economic evaluations have appeared in the medical literature. The aims of this study were to undertake a systematic review of the performance of ${ }^{99 \mathrm{~m} T c-\mathrm{MIBI} \text { imaging }}$ in the assessment of treatment resistance in lung cancer and to use the findings of the review in a decision tree analysis of the potential cost-effectiveness of ${ }^{99 \mathrm{~m}} \mathrm{Tc}-\mathrm{MIBI}$ imaging in selecting lung cancer patients for chemotherapy. Methods: This study included a systematic review of the literature and a meta-analysis together with a cost-effectiveness analysis of studies with a decision tree analysis model. Results: Analysis of the studies revealed that the overall sensitivity of $99 \mathrm{mTC}-\mathrm{MIBI}$ in identifying responders to chemotherapy was $94 \%$, the specificity was $90 \%$, and the accuracy was $92 \%$. The sensitivity analysis revealed an incremental cost-effectiveness ratio of greater than $£ 30,000(\sim \$ 42,900)$ for the strategy of treating all patients to recover the small loss of life expectancy $(7.5 \mathrm{~d})$ associated with the use of $99 \mathrm{mTc}-\mathrm{MIBI}$ to preselect patients for chemotherapy. Conclusion: ${ }^{99 m}$ TC-MIBI SPECT can accurately predict which patients with lung cancer will respond to chemotherapy. The use of ${ }^{99 \mathrm{~m} T c-M I B I}$ to preselect patients for chemotherapy has the potential to yield significant cost savings in the health care system without a significant loss of life expectancy for patients.

Received Jul. 16, 2008; revision accepted Oct. 8, 2008.

For correspondence or reprints contact: Hosahalli K. Mohan, Department of Nuclear Medicine, Ground Floor, New Guys House, Guys Hospital, St. Thomas St., London SE1 9RT, United Kingdom.

E-mail: mohanhk@hotmail.com

COPYRIGHT ๑ 2009 by the Society of Nuclear Medicine, Inc.
Key Words: oncology; SPECT; chemotherapy; cost-effectiveness; lung cancer; $99 \mathrm{mTC}$ TIBI

J Nucl Med 2009; 50:376-381

DOI: 10.2967/jnumed.108.055988

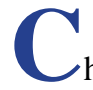

hemotherapy in lung cancer was first studied in the late 1960s and has been used extensively since then $(1,2)$. The use of chemotherapy has resulted in a 5 -fold increase in median survival and a long-term disease-free survival of over $3 \mathrm{y}$ in $5 \%-10 \%$ of patients with small cell lung cancer and in patients with non-small cell lung cancer as well. ${ }^{99 \mathrm{~m}} \mathrm{Tc}-\mathrm{methoxyisobutylisonitrile}\left({ }^{99 \mathrm{~m}} \mathrm{Tc}-\mathrm{MIBI}\right)$ has been used as an imaging agent in the evaluation of breast, bone, thyroid, and lung tumors (3-6). It has been shown that ${ }^{99 m}$ Tc-MIBI is a transport substance recognized by multidrug resistance (MDR)-related P glycoprotein (P-gp) and that tumor cell accumulation is enhanced by inhibition of the efflux transport function (7). These results provided the basis for clinical studies that investigated the role of ${ }^{99 \mathrm{~m}} \mathrm{Tc}-$ MIBI in predicting the response to chemotherapy in patients with lung cancer (8-15).

There is increasing concern about the economic burden on health care providers because of the increasing costs of management coupled with increasing drug resistance. The number of economic analysis studies has increased greatly in the last 2 decades (16) in an increasingly cost-conscious environment. Increasing concern about containing costs and overall spending has resulted in the evaluation of imaging as part of strategies for managing the costs associated with the use of imaging for specific clinical conditions (17-19). This situation is particularly relevant for strategies whose adoption and use result in a significant financial commitment from the health care system. However, to date, no studies have assessed the cost-effectiveness of ${ }^{99 \mathrm{~m}} \mathrm{Tc}-\mathrm{MIBI}$ in predicting the response to chemotherapy; in addition, this use of ${ }^{99 \mathrm{~m}} \mathrm{Tc}-$ MIBI imaging has not been considered in the formulation of 
clinical guidelines for lung cancer, such as those published by the U.K. National Institute for Clinical Excellence (NICE) (20).

The aims of this study were to undertake a systematic review of the performance of ${ }^{99 \mathrm{~m}} \mathrm{Tc}-\mathrm{MIBI}$ imaging in the assessment of treatment resistance in lung cancer and to use the findings of the review in a decision tree analysis of the potential cost-effectiveness of ${ }^{99 \mathrm{~m}} \mathrm{Tc}-\mathrm{MIBI}$ imaging in selecting lung cancer patients for chemotherapy.

\section{MATERIALS AND METHODS}

\section{Systematic Literature Review}

We performed a systematic analysis of the available literature on the use of $99 \mathrm{mTc}-\mathrm{MIBI}$ in predicting the clinical response to chemotherapy in lung cancer. We followed the guidelines set out in a recent publication by Matowe and Gilbert (21) for gathering and evaluating evidence from the literature on the efficacy of imaging in systematic reviews. MEDLINE was searched from 1966 through July 2007. Additional studies were identified by searching the Internet for the Agency for Health Care Policy and Research, the Canadian Medical Association Clinical Practice Guidelines Database, and the Centers for Disease Control and Prevention. Further Internet searches were performed with the Google search engine. We searched PubMed with the MeSH terms "mibi and lung cancer" and "mibi and chemotherapy response" and "mibi and chemoresistance," with the search being limited to "humans" and "English language." Case reports were also excluded.

Only studies in which the initial imaging had been performed within $30 \mathrm{~min}$ of tracer injection were included.

\section{Meta-Analysis}

A meta-analysis was used to derive the overall prevalence of responders, the sensitivity and specificity of $99 \mathrm{mTc}$-MIBI SPECT, and the $95 \%$ confidence intervals (CIs) for the parameters.

\section{Cost-Effectiveness Analysis (CEA)}

CEA is increasingly used in the health care sector and is designed to answer the question, "Is it worth the extra money to implement strategy B instead of strategy A?" A common approach is to examine a currently accepted standard of care against a new, more expensive strategy that improves outcomes. The consequences of alternative strategies are measured in physical units rather than just monetary values, for example, life years saved. Hospitals, managed care organizations, self-insured employers, researchers, and individual physicians have used this technique for the development of new management guidelines, either formally or informally.

In this study, we considered 3 strategies for the management of lung cancer: basic supportive care, which was the strategy with the lowest cost and the shortest life expectancy; treatment of all

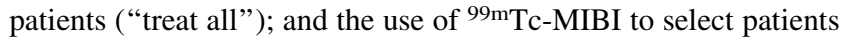
for treatment.

A decision tree analysis model was used for each strategy (Fig. 1). The contribution of ${ }^{99 \mathrm{~m}} \mathrm{Tc}-\mathrm{MIBI}$ SPECT in the prechemotherapy evaluation was assessed by decision tree analysis with Extend Software (Imagine That, Inc.) and blocks used in the decision tree model software from the Crump Institute, University of California at Los Angeles. The imaging strategy was compared with the baseline strategies of chemotherapy for all patients and palliative care for all patients. For the imaging strategy, it was assumed that all patients would undergo a ${ }^{99 \mathrm{~m}} \mathrm{Tc}-\mathrm{MIBI}$ SPECT study before chemotherapy and would have chemotherapy only if their ${ }^{99 \mathrm{~m}} \mathrm{Tc}-\mathrm{MIBI}$ SPECT study results were positive. The sensitivity and specificity of SPECT, along with their $95 \%$ CIs, were determined from patient data. The cost of the SPECT study was obtained from the NICE guidelines for myocardial perfusion imaging with ${ }^{99 \mathrm{~m}} \mathrm{Tc}-\mathrm{MIBI}$ SPECT (22). The costs of basic supportive care and chemotherapy were obtained from the National Health Service health technology assessment report (23) and were based on the most cost-effective paclitaxel-based therapy, reflecting the chemotherapeutic approach adopted in some of the ${ }^{99 \mathrm{~m}} \mathrm{Tc}-\mathrm{MIBI}$ studies. The life expectancies achieved with basic supportive care and chemotherapy were also obtained from randomized trials summarized in the NHS HTA report (23). The survival benefit of chemotherapy was adjusted to account for the prevalence of responders, as determined from the meta-analysis.

\section{Outcome}

For each strategy, cost, life expectancy gained, and cost benefit were calculated. The incremental cost-effectiveness ratio (ICER) was used to compare the cost-effectiveness of different strategies, according to the following equation: ICER $=($ cost of strategy $1-$ cost of strategy 2$) /($ effectiveness of strategy 1 - effectiveness of strategy 2).

We adopted an ICER of $£ 30,000(\sim \$ 42,900)$ per life year, in keeping with the threshold used by NICE since 1999.

Sensitivity analysis was used to assess the impact of variations in baseline assumptions on the study results. Values for the prevalence of responders and the sensitivity and specificity of the ${ }^{99 \mathrm{~m}} \mathrm{Tc}-\mathrm{MIBI}$ study for identifying responders were varied within the range of 95\% CIs from the meta-analysis. Chemotherapy costs were varied as described in the NICE guidelines (20). A worst-case scenario in which the SPECT cost was doubled was also considered.

\section{RESULTS}

\section{Literature Review and Meta-Analysis}

Overall, this search produced 56 articles from May 1966 through October 2007; 16 studies of those studies were identified as being common to the 3 search terms. Of these 16,8 were not included because 2 studies were case reports, 4 studies used a different imaging agent (tetrofosmin), and 2 studies had initial imaging times that were more than 30 min after the injection of ${ }^{99 m}$ Tc-MIBI.

A total of 235 patients were included in the 8 studies. The total number of responders, including both complete and partial responders, was 116, resulting in an overall prevalence of 0.49 . The $95 \%$ CIs were between 0.44 and 0.55 . The overall sensitivity of $99 \mathrm{~m}$ Tc-MIBI in identifying responders to chemotherapy was $94 \%$, the specificity was $90 \%$, and the accuracy was $92 \%$.

\section{CEA}

The baseline assumptions used in the decision tree modeling are summarized in Table 1 . The overall results of the decision tree analysis are summarized in Table 2.

Under baseline conditions, the imaging strategy was less expensive than the treat-all strategy but resulted in a small loss of overall life expectancy $(7.5 \mathrm{~d})$. The imaging strategy 


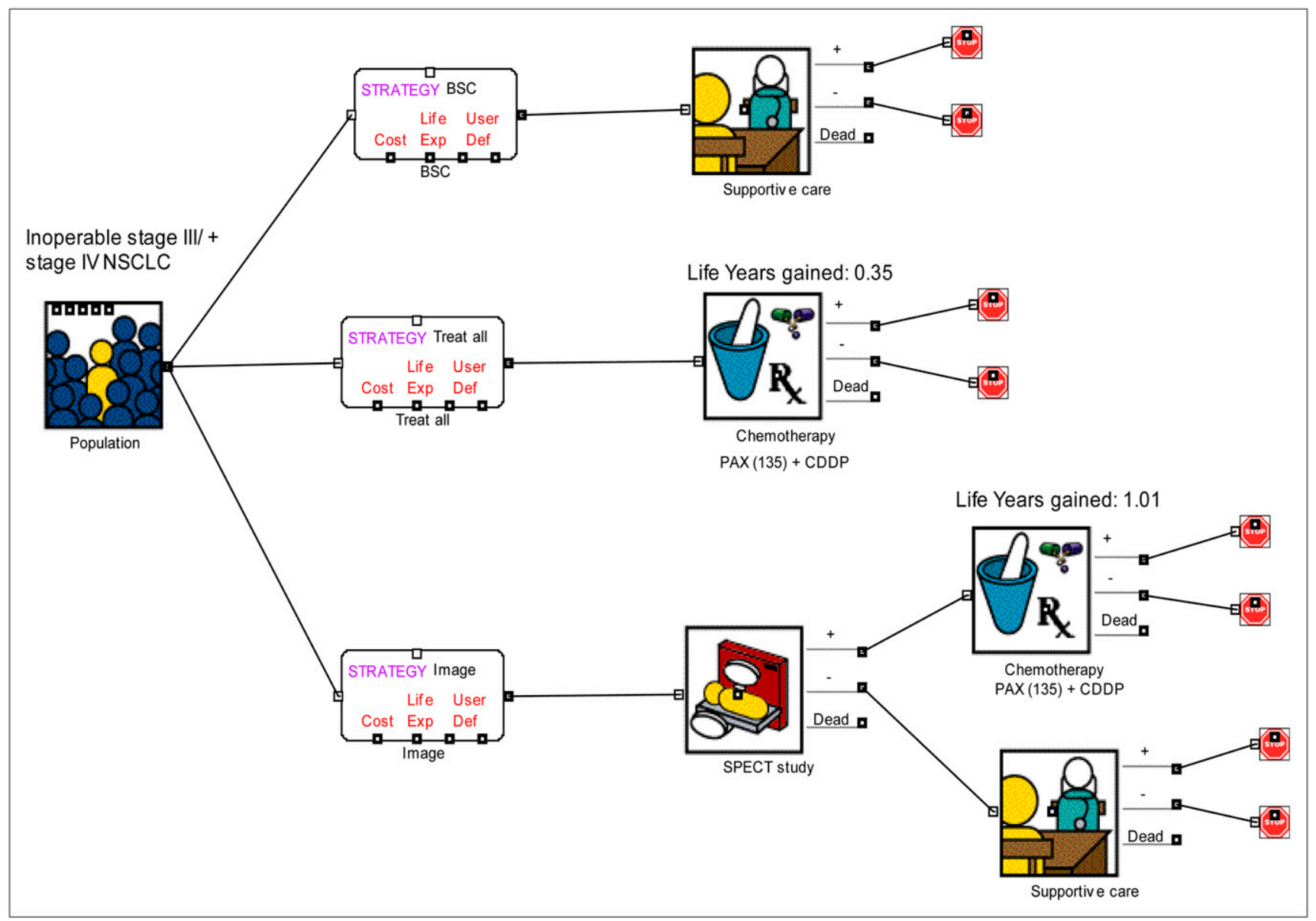

FIGURE 1. Decision tree analysis model based on NICE guidelines. BSC = basic supportive care; CDDP $=$ cisplatin; Def $=$ definition; Exp = expectancy; NSCLC = non-small cell lung cancer; PAX = paclitaxel.

was the most cost-effective of all 3 strategies. The ICER for the treat-all strategy compared with the imaging strategy indicated that the cost of regaining the small loss of life expectancy was $£ 60,051(\sim \$ 85,873)$ per life year.

One-way sensitivity analyses examining the costeffectiveness of each strategy with various prevalence, SPECT sensitivity, and SPECT specificity values showed that the strategy of using ${ }^{99 \mathrm{~m}} \mathrm{Tc}-\mathrm{MIBI}$ to preselect patients for chemotherapy was always the least expensive and the most cost-effective. The maximum loss of life expectancy resulting from the imaging strategy compared with the treat-all strategy was $15 \mathrm{~d}$. The ICER for the treat-all strategy compared with the strategy of using ${ }^{99 \mathrm{~m} T c-M I B I}$ remained greater than $£ 30,000(\sim \$ 42,900)$ under all conditions.

The sensitivity analysis considering the cost of chemotherapy showed that only when the cost of chemotherapy was

\section{TABLE 1. Parameters Used in Decision Tree Modeling}

\begin{tabular}{|c|c|c|c|}
\hline Parameter & Baseline & Limits & Source \\
\hline Prevalence of responders & 0.49 & $0.44-0.55$ & Meta-analysis of studies $6-13$ \\
\hline SPECT sensitivity & 0.94 & $0.88-0.97$ & Meta-analysis of studies $6-13$ \\
\hline SPECT specificity & 0.90 & $0.83-0.94$ & Meta-analysis of studies $6-13$ \\
\hline Cost of SPECT* ${ }^{\star}$ & $265(\sim 379)$ & & NICE guidelines (22) \\
\hline Cost of chemotherapy* & $6,283(\sim 8,985)$ & & HTA report (23) \\
\hline Cost of basic supportive care ${ }^{\star}$ & $3,210(\sim 4,590)$ & & HTA report (23) \\
\hline Life expectancy of basic supportive care & 0.433 y & & HTA report (23) \\
\hline $\begin{array}{l}\text { Life expectancy with treatment success } \\
\text { adjusted for prevalence of responders }\end{array}$ & $1.13 y$ & & HTA report (23) \\
\hline
\end{tabular}


TABLE 2. Results of Decision Tree Analysis*

\begin{tabular}{|c|c|c|c|c|c|c|c|c|c|c|}
\hline \multirow[b]{2}{*}{ Parameter } & \multicolumn{3}{|c|}{ Cost $(£)$} & \multicolumn{3}{|c|}{ Survival (life years) } & \multicolumn{3}{|c|}{ Cost-effectiveness ( $£ /$ life year) } & \multirow[b]{2}{*}{$\begin{array}{l}\text { ICER }(£) \text { for } \\
\text { treat all } \\
\text { vs. imaging }\end{array}$} \\
\hline & Treat all & Imaging & $\begin{array}{c}\text { Basic } \\
\text { supportive } \\
\text { care }\end{array}$ & Treat all & Imaging & $\begin{array}{c}\text { Basic } \\
\text { supportive } \\
\text { care }\end{array}$ & Treat all & Imaging & $\begin{array}{c}\text { Basic } \\
\text { supportive } \\
\text { care }\end{array}$ & \\
\hline Baseline prevalence & 6,283 & 5,047 & 3,210 & 0.78 & 0.76 & 0.43 & 8,093 & 6,678 & 7,408 & 60,051 \\
\hline Lower 95\% Cl & 6,283 & 4,918 & & 0.74 & 0.72 & & 8,475 & 6,804 & & 73,860 \\
\hline Upper 95\% Cl & 6,283 & 5,202 & & 0.82 & 0.80 & & 7,678 & 6,542 & & 46,795 \\
\hline \multicolumn{11}{|l|}{ SPECT sensitivity } \\
\hline Lower 95\% Cl & 6,283 & 4,980 & & 0.78 & 0.74 & & 8,055 & 6,729 & & 31,000 \\
\hline Upper 95\% Cl & 6,283 & 5,120 & & 0.78 & 0.77 & & 8,055 & 6,649 & & 110,800 \\
\hline \multicolumn{11}{|l|}{ SPECT specificity } \\
\hline Lower $95 \% \mathrm{Cl}$ & 6,283 & 5,180 & & 0.78 & 0.76 & & 8,055 & 6,815 & & 52,500 \\
\hline Upper $95 \% \mathrm{Cl}$ & 6,283 & 5,011 & & 0.78 & 0.76 & & 8,055 & 6,593 & & 60,500 \\
\hline \multicolumn{11}{|l|}{ Chemotherapy cost } \\
\hline Lower limit & 3,700 & 3,729 & & 0.78 & 0.76 & & 4,744 & 4,907 & & $-1,450$ \\
\hline Upper limit & 18,700 & 11,529 & & 0.78 & 0.76 & & 24,087 & 15,256 & & 348,407 \\
\hline \multicolumn{11}{|l|}{ SPECT cost doubled } \\
\hline Lower limit & 3,700 & 3,994 & & 0.78 & 0.76 & & 4,766 & 5,285 & & $-14,324$ \\
\hline Upper limit & 18,700 & 11,794 & & 0.78 & 0.76 & & 24,087 & 15,606 & & 335,530 \\
\hline
\end{tabular}

as low as $£ 3,700(\sim \$ 5,291)$ was the treat-all strategy less expensive and more effective than the imaging strategy, with an ICER of $-£ 1,450(\sim-\$ 2,074)$. Even in the worst-case scenario, when the SPECT cost was doubled, the ICER was less than $£ 30,000(\sim \$ 42,900)$ only when the chemotherapy cost was as low as $£ 5,575(\sim \$ 7,972)$ (Fig. 2).

\section{DISCUSSION}

The current decision analysis represents a populationbased approach intended to identify the algorithm providing the most cost-effective management of lung cancer chemotherapy. We did not attempt to address how a physician should manage the care of an individual patient. Patient preferences and concerns must be considered when determining how to use imaging tests with different degrees of certainty or uncertainty.
The current strategy used for the management of surgically nonresectable lung cancer is either chemotherapy or just basic supportive care for patients with terminal disease. However, with modern imaging technologies, including CT, MRI, and PET/CT, the management of lung cancer has been altered significantly. Early diagnosis with newer technology and the development of newer chemotherapy drugs have led to aggressive management of the disease. However, these changes have placed great stresses on both finances and the resources of the health care system.

Since the study of Piwnica-Worms et al. (7) described the use of ${ }^{99 \mathrm{~m} T c-M I B I}$ in the identification of MDR mediated by P-gp, many studies have been undertaken to examine the usefulness of ${ }^{99 \mathrm{~m}} \mathrm{Tc}-\mathrm{MIBI}$ in identifying drug resistance in tumors. Such study is essential considering the toxic nature of chemotherapy. Also, it is important to deliver a drug to patients who will respond to it rather than to patients who will be resistant to its effects, resulting in better clinical effectiveness

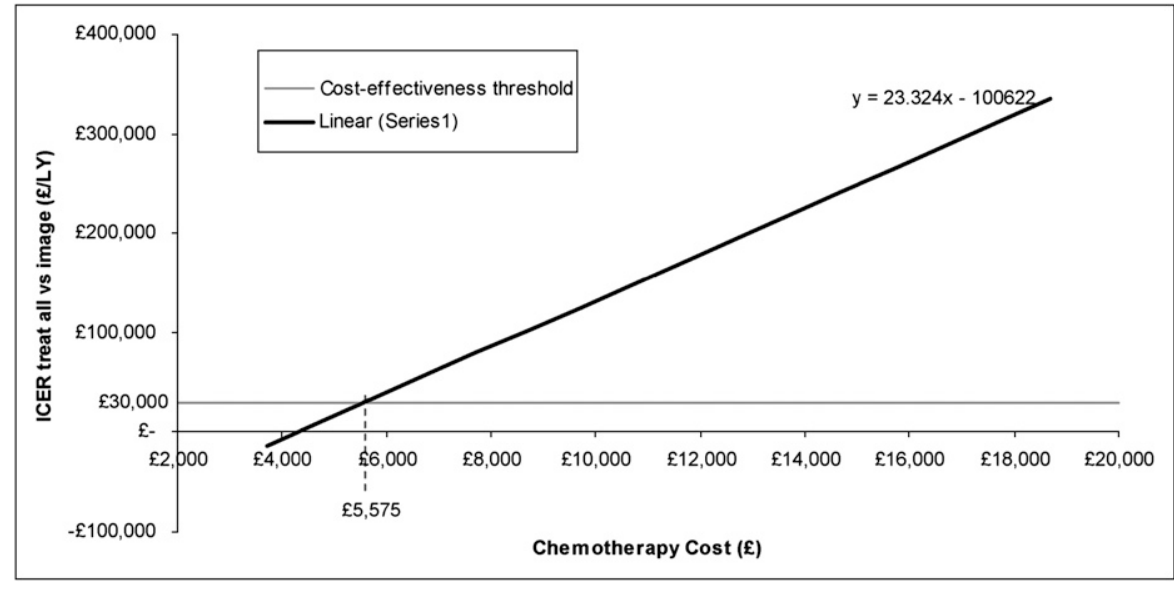

FIGURE 2. Chart plotting ICER for treat-all strategy vs. cost of chemotherapy. $L Y=$ life years. 
and reducing the side effects of failed therapy on the rest of the body in chemotherapy-resistant patients. Such achievements also translate into improved cost-effectiveness, as shown by our analysis.

The number of published studies examining the effectiveness of ${ }^{99 \mathrm{~m}} \mathrm{Tc}-\mathrm{MIBI}$ in preselecting patients before chemotherapy in lung cancer is limited. However, it has been observed that when ${ }^{99 \mathrm{~m}} \mathrm{Tc}-\mathrm{MIBI}$ is used, it is very effective in differentiating responders from nonresponders.

The treat-all strategy proved to be more costly than the imaging strategy even when the lowest limits of sensitivity and specificity for the imaging strategy and the lowest prevalence of responders were considered. The added benefit of the treat-all strategy translated into a survival gain of only $7.5 \mathrm{~d}$ compared with the results obtained from imaging patients with ${ }^{99 \mathrm{~m}} \mathrm{Tc}-\mathrm{MIBI}$ to preselect responders. Only when the cost of chemotherapy was less than $£ 5,575(\sim \$ 7,972)$ was it more cost-effective (i.e., $<£ 30,000[<\sim \$ 42,900]$ per life year gained) to treat all patients. However, the cost of chemotherapy, as outlined by NICE guidelines, ranged up to $£ 18,700$, with a median cost of $£ 11,000$; these costs justify the use of an efficient preselection technique to identify responders. The other important issue to consider is the loss of quality of life because of morbidity and mortality associated with toxic chemotherapy drugs in nonresponders. These facts make a strong case for tailoring therapy to patients.

Different parameters have been used in various studies to identify chemotherapy responders. These include initial uptake of ${ }^{99 \mathrm{~m}} \mathrm{Tc}-\mathrm{MIBI}$, delayed retention, percentage washout, and retention index. The best parameter for predicting the response to chemotherapy was the degree of initial ${ }^{99 \mathrm{~m}} \mathrm{Tc}-$ MIBI uptake by the tumor, seen in 7 of the 8 studies included (7,9,11-15). In all of these studies, lung cancer patients who had less ${ }^{99 \mathrm{~m} T c-M I B I}$ uptake were less likely to respond to chemotherapy than those who had more uptake. However, some overlap in initial tumor uptake between responders and nonresponders reduced the accuracy of the studies. Bom et al. (15) reported that with dipyridamole, which is a P-gp modulator, they were able to improve the accuracy of identifying responders by nearly 2 -fold. A reduction in the initial uptake of ${ }^{99 \mathrm{~m} T c-M I B I}$ followed by a subsequent increase after dipyridamole infusion was a strong negative predictor of the response to chemotherapy. They concluded that dipyridamole- ${ }^{99 \mathrm{~m}}$ Tc-MIBI SPECT could help physicians predict the response to chemotherapy in patients with small cell lung cancer. These findings suggested that $\mathrm{P}$-gp expressed in a tumor was responsible for the reduction in initial uptake.

Tumor ${ }^{99 \mathrm{~m}} \mathrm{Tc}-\mathrm{MIBI}$ washout rates, however, were not found to be very reliable in identifying nonresponders. Tumors in some responders showed ${ }^{99 \mathrm{~m} T \mathrm{Tc}-\mathrm{MIBI} \text { washout }}$ as early as tumors in nonresponders. Early imaging in all 8 studies included was performed within $30 \mathrm{~min}$ of the intravenous injection of ${ }^{99 \mathrm{~m}} \mathrm{Tc}-\mathrm{MIBI}$. In 2 studies $(24,25)$ that were not included in the present investigation, the chest was imaged more than 30 min after the injection of ${ }^{99 \mathrm{~m}} \mathrm{Tc}-\mathrm{MIBI}$, a factor that may explain the reduced tumor uptake seen in responders on early imaging. There was no significant difference in ${ }^{99 \mathrm{~m}} \mathrm{Tc}$-MIBI uptake between non-small cell lung cancer and small cell lung cancer in these 8 studies.

The costs used for modeling in the present study were from the U.K. health care system. Although health care costs vary from country to country, the relative proportions are likely to be similar; therefore, similar results would be expected to be obtained in comparisons of various decision pathways.

CEA can be used not only to guide clinical practice but also to prioritize clinical trials on the basis of the likely impact on evidence-based clinical practice (26,27). Given the relatively small numbers of cases in the literature reporting the use of ${ }^{99 \mathrm{~m}} \mathrm{Tc}-\mathrm{MIBI}$ to predict the response to treatment, the results of our study may not be sufficient to influence clinical practice without further randomized controlled trials. However, our results do indicate that such trials should be a high priority for clinical research.

\section{CONCLUSION}

The results indicate that ${ }^{99 \mathrm{~m}} \mathrm{Tc}-\mathrm{MIBI}$ SPECT has excellent sensitivity and specificity in predicting chemotherapy responders and nonresponders. The use of ${ }^{99 \mathrm{~m} T c-M I B I}$ to preselect chemotherapy responders would result in significant cost savings for the health care system. In our opinion, the cost of treating all patients outweighs the modest gain $(7.5 \mathrm{~d})$ in life expectancy achieved. The data from the present study indicate a high priority for prospective randomized trials to confirm the role of ${ }^{99 m}$ Tc-MIBI in patients with lung cancer.

\section{REFERENCES}

1. Smil EF, Poslmus PE. Chemotherapy of small-cell lung cancer. In: Carney DN, ed., Lung Cancer. Avon, U.K.: The Bath Press; 1995:156-172.

2. Berlin J, Schiller JH. Chemotherapy of small-cell carcinoma of the lung. In: Johnson BE, Johnson DH, eds. Lung Cancer. New York, NY: Wiley-Liss; 1995:247-261.

3. Burak Z, Argon M, Memis A, et al. Evaluation of palpable breast masses with 99mTc-MIBI: a comparative study with mammography and ultrasonography. Nucl Med Commun. 1994;15:604-612.

4. Caner B, Kitapçl M, Unlü M, et al. Technetium-99m-MIBI uptake in benign and malignant bone lesions: a comparative study with technetium-99m-MDP. J Nucl Med. 1992;33:319-324.

5. Yen T, Lin H, Lee C, et al. The role of technetium- $99 \mathrm{~m}$ sestamibi whole-body scans in diagnosing metastatic Hürthle cell carcinoma of the thyroid gland after total thyroidectomy: a comparison with iodine-131 and thallium-201 wholebody scans. Eur J Nucl Med. 1994;21:980-983.

6. Hassan IM, Sahweil A, Constantinides C, et al. Uptake and kinetics of Tc-99m hexakis 2-methoxy isobutyl isonitrile in benign and malignant lesions in the lungs. Clin Nucl Med. 1989;14:333-340.

7. Piwnica-Worms D, Chiu ML, Budding M, et al. Functional imaging of multidrug-resistant P-glycoprotein with an organo-technetium complex. Cancer Res. 1993;53:977-984.

8. Yüksel M, Cermik TF, Doğanay L, et al. ${ }^{99 \mathrm{~m}} \mathrm{Tc}-\mathrm{MIBI}$ SPET in non-small cell lung cancer in relationship with Pgp and prognosis. Eur J Nucl Med Mol Imaging. 2002;29:876-881.

9. Kao A, Shiun SC, Hsu NY, Sun SS, Lee CC, Lin CC. Technetium-99m methoxyisobutylisonitrile chest imaging for small-cell lung cancer: relationship to chemotherapy response (six courses of combination of cisplatin and etoposide) and p-glycoprotein or multidrug resistance related protein expression. Ann Oncol. 2001;12:1561-1566. 
10. Nishiyama Y, Yamamoto Y, Satoh K, et al. Comparative study of Tc-99m MIBI and Tl-201 SPECT in predicting chemotherapeutic response in non-small-cell lung cancer. Clin Nucl Med. 2000;25:364-369.

11. Yüksel M, Cermik TF, Karlikaya C, et al. Monitoring the chemotherapeutic response in primary lung cancer using ${ }^{99 \mathrm{~m} T c-M I B I}$ SPET. Eur J Nucl Med. 2001;28:799-806.

12. Kao CH, Hsieh JF, Tsai SC, Ho YJ, Lee JK. Quickly predicting chemotherapy response to paclitaxel-based therapy in non-small cell lung cancer by early technetium-99m methoxyisobutylisonitrile chest single-photon-emission computed tomography. Clin Cancer Res. 2000;6:820-824.

13. Yamamoto Y, Nishiyama Y, Fukunaga K, Satoh K, Fujita J, Ohkawa M. ${ }^{99 \mathrm{~m}}$ TcMIBI SPECT in small cell lung cancer patients before chemotherapy and after unresponsive chemotherapy. Ann Nucl Med. 2001;15:329-335.

14. Ceriani L, Giovanella L, Bandera M, Beghe B, Ortelli M, Roncari G. Semi-

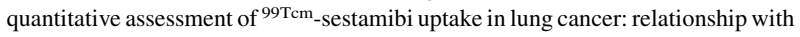
clinical response to chemotherapy. Nucl Med Commun. 1997;18:1087-1097.

15. Bom HS, Lim SC, Kim YC, et al. Dipyridamole modulated Tc-99m sestamibi lung SPECT in small cell lung cancer. Clin Nucl Med. 1999;24:97-101.

16. Blackmore CC, Magid DJ. Methodologic evaluation of the radiology costeffectiveness literature. Radiology. 1997;203:87-91.

17. Miles KA. An approach to demonstrating cost effectiveness of diagnostic imaging modalities in Australia illustrated by Positron Emission Tomography. Australas Radiol. 2001;45:9-18.

18. Scott WJ, Shepherd J, Gambhir SS. Cost effectiveness of FDG-PET for staging non small cell lung cancer: a decision tree analysis. Ann Thorac Surg. 1998; $66: 1876-1883$.
19. Dietlein M, Weber K, Gandjour A, et al. Cost effectiveness of FDG-PET for the management of potentially operable non-small cell lung cancer: priority for a PETbased strategy after nodal-negative CT results. Eur J Nucl Med. 2000;27:15981609.

20. National Institute for Health and Clinical Excellence. Lung cancer. February 2005. http://www.nice.org.uk/nicemedia/pdf/CG024niceguidelineword.doc. Accessed May 2008.

21. Matowe L, Gilbert FJ. How to synthesize evidence for imaging guidelines. Clin Radiol. 2004;59:63-68.

22. National Institute for Clinical Excellence. Myocardial perfusion scintigraphy for the diagnosis and management of angina and myocardial infarction. Technology appraisal 73. November 2003. http://www.nice.org.uk/nicemedia/pdf/ TA073guidance.pdf. Accessed January 19, 2009.

23. Clegg A, Scott DA, Hewitson P, Sidhu M, Waugh N. Clinical and cost effectiveness of paclitaxel, docetaxel, gemcitabine and vinorelbine in non-small cell lung cancer: a systematic review. Thorax. 2002;57:20-28.

24. Dirlik A, Burak Z, Goksel T, et al. The role of Tc-99m sestamibi imaging in predicting clinical response to chemotherapy in lung cancer. Ann Nucl Med. 2002;16:103-108.

25. Akgun A, Cok G, Karapolat I, Goksel T, Burak Z. Tc-99m MIBI SPECT in prediction of prognosis in patients with small cell lung cancer. Ann Nucl Med. 2006;20:269-275.

26. Dirlik A, Burak Z, Goksel T, et al. Primer on cost-effectiveness analysis. Eff Clin Pract. 2000;5:253-255.

27. Chilcott J, Brennan A, Booth A, Karnon J, Tappenden P. The role of modelling in prioritising and planning clinical trials. Health Technol Assess. 2003;7:1-125. 